\title{
Dilemas éticos e a elaboração de relatórios sociais
}

\author{
Gabriella Mariano Munhoz Zeneratti \\ Ministério Público do Estado do Paraná (MPPR)
}

\author{
Olegna de Souza Guedes \\ Universidade Estadual de Londrina (UEL)
}

\section{Dilemas éticos e a elaboração de relatórios sociais}

Resumo: O artigo tematiza a dimensão ética quando da elaboração dos relatórios sociais construídos no cotidiano de uma instituição que executa a medida socioeducativa de internação. Recorre-se ao uso da pesquisa bibliográfica e documental. A coleta de dados desta última construída a partir de relatórios sociais produzidos por assistentes sociais inseridos em instituições de privação de liberdade para adolescentes infratores e teve seu tratamento à luz da análise de conteúdo. Dentre os resultados da pesquisa, destaca-se a identificação de dilemas éticos que se inscrevem entre os objetivos institucionais e os profissionais. São dilemas que desafiam os profissionais a ultrapassar tendências em afirmar à reprodução de valores morais avessos às possibilidades de ampliação de ações emancipatórias no cotidiano de uma instituição que executa medida socioeducativa em regime fechado.

Palavras-chave: Ética. Relatório Social. Dilemas éticos. Cotidiano.

\section{Ethical Dilemmas and the Drafting of Social Reports}

Abstract: The article conceptualizes the ethical dimensions involved in the drafting of social reports prepared in daily work at an institution that implements socio-educational measures through internment. It uses bibliographic and document research, based on content analysis of social reports produced by social assistants working at institutions of incarceration for adolescents. The research identifies ethical dilemmas within the institutional and professional objectives. These dilemmas challenge professionals to go beyond the tendency to affirm the reproduction of moral values that impede the possibilities for expanding emancipatory actions in the daily work of an institution that executes educational social measures for people in confinement.

Keywords: Ethics. Social report. Ethical dilemmas. Daily work. 


\section{Introdução}

No cotidiano de trabalho do assistente social, ruídos produzidos pela sociabilidade burguesa exigem a capacidade para sacudir as aparências e desvelar contradições inerentes ao modo de produzir/consumir que a mantém, bem como os valores por ela reproduzidos. Eis um dos grandes desafios: refletir sobre o exercício profissional a partir da relação dialética entre trabalho consciente e constrangimentos do trabalho alienado. A ética, uma das mediações constitutivas dessa relação, possibilita a passagem das experiências vividas sob a moralidade rígida, repetitiva e, muitas vezes, avessa ao humano-genérico, para as que ampliam a consciência, a liberdade e incidem sob uma nova práxis.

Essas premissas motivaram e orientaram a construção de uma pesquisa com vistas a elaboração de dissertação de mestrado que apresentou como objetivo geral a análise da dimensão ética que orienta os assistentes sociais na construção de relatórios sociais no cotidiano de uma instituição que executa medida socioeducativa de internação. Essa pesquisa, que tem parte de seus resultados apresentada neste artigo, caracterizou-se como aplicada e de caráter explicativo. Orientou-se, do ponto de vista metodológico, por revisão bibliográfica e análise documental.

Esta última teve como fonte, além de normativas e legislações, um conjunto de relatórios sociais elaborados por assistentes sociais que trabalham em instituições que executam a medida socioeducativa de internação no Estado do Paraná: os Centros de Socioeducação (CENSE). Foram examinados 18 relatórios sociais, dentre os 36 encaminhados ao Fórum da Comarca $A^{1}$, no período de janeiro a março de 2014. São relatórios multidisciplinares e, por esta razão, não foram analisados em sua íntegra. A liberação desses documentos pelo poder judiciário foi restrita aos itens referentes ao relatório social.

A escolha desses documentos como fonte empírica da pesquisa ocorreu a partir da constatação de que eles traduzem senso moral, juízo de valores e sinalizam a reprodução ou crítica do senso comum, no que se refere ao campo axiológico. São de suma importância na vida laborativa dos assistentes sociais inseridos na área sociojurídica², e, ao mesmo tempo, definem a vida de indivíduos sociais que, como muitos, sofrem o processo de desumanização decorrente da sociedade fundada na propriedade privada.

A construção do relatório social tem por objetivo a avaliação da continuidade, ou não, da medida socioeducativa de internação dos adolescentes privados de liberdade. Tal dimensão aparece, sobretudo, com a apresentação de dilemas que decorrem da complexa relação entre os objetivos profissionais e institucionais e que desafiam os assistentes sociais em suas atribuições específicas e indicam a ética profissional como necessária para enfrentá-los.

Socializar aspectos dessa pesquisa é o objetivo deste artigo. Nele, pretende-se apresentar aspectos da ética profissional que devem orientar o cumprimento de uma das funções privativas do assistente social: a construção do relatório social. Com este propósito, ele foi organizado em três seções. A primeira apresenta aspectos institucionais a serem considerados para análise do relatório social dentro de um Centro de Socioeducação. A segunda seção expõe uma breve análise da dimensão ética que se constrói na complexa relação entre os objetivos profissionais e institucionais nessa instituição. A última seção apresenta alguns dilemas éticos a serem considerados para a construção cotidiana da ética profissional.

\section{A construção de relatórios sociais nos CENSEs: uma das atribuições profissionais dos assistentes sociais}

Os relatórios sociais aos quais aludimos neste artigo, por um lado, devem ter como subsídios norteadores a proposta político-pedagógica institucional dos CENSEs ${ }^{3}$, fundamentada pelos Cadernos do Instituto de Ação Social do Paraná (IASP) ${ }^{4}$, nos quais são definidas as atribuições funcionais dos assistentes sociais desses CENSEs e, dentre elas, a de "elaborar os estudos de caso e relatórios técnicos dos adolescentes" e a de "prestar atendimento às famílias dos adolescentes, colhendo informações, orientando e propondo formas de manejo das situações sociais” (INSTITUTO DE AÇÃO SOCIAL DO PARANÁ, 2006, p. 78).

A instituição deixa clara a expectativa em relação ao profissional de Serviço Social. Não há equívocos nestas atribuições, se foram analisadas, apenas, a partir da interpretação institucional; ou seja, para garantir o projeto político-pedagógico institucional no que tange à política para adolescentes em conflito com a lei no Paraná, na execução da medida socioeducativa de internação, o assistente social deve contribuir com sua especificidade numa perspectiva interdisciplinar para a (re)educação da vida social dos adolescentes apreendidos.

Destacamos que o projeto político pedagógico pretende demarcar uma nova perspectiva institucional para o trabalho com adolescentes em cumprimento de medida socioeducativa de internação e semiliberdade: a socioeducação. Porém trata-se de uma interpretação em que se oculta à responsabilização penal juvenil 
e se reitera a imagem construída no Estatuto da Criança e do Adolescente (ECA) que disfarça a natureza e a finalidade punitiva sob um pseudo conteúdo socioeducativo (SILVA, 2011). Na concepção de Silva (2011, p. 173):

historicamente o conteúdo da assistência e da proteção e, agora, da socioeducação tem funcionado como um instrumento facilitador do controle não só social como penal de adolescente inimputável. O socioeducativo disfarça os conteúdos repressivos, coercitivos e punitivos das medidas para atingir a finalidade de defesa social.

A compreensão destes aspectos é necessária pois eles figuram como mediações da realidade institucional e interferem, de forma direta e indireta, na construção dos relatórios sociais nos CENSEs, os quais estão medularmente vinculados ao cotidiano profissional contribuindo para o cumprimento do procedimento institucional. Uma das atribuições instituídas para o assistente social, nessa instituição, são esses relatórios. ${ }^{5}$

Trata-se de uma atribuição profissional, que para além das orientações dos Cadernos Iaspe (mencionados anteriormente), está vinculada às normativas do Sistema Nacional de Medidas Socioeducativas (SINASE) que, no seu artigo 42 estabelece: "as medidas socioeducativas de liberdade assistida, de semiliberdade e de internação deverão ser reavaliadas no máximo a cada seis meses [...]” e no artigo 43: "a reavaliação da manutenção, da substituição ou da suspensão das medidas de meio aberto ou de privação da liberdade e do respectivo plano individual pode ser solicitada a qualquer tempo, a pedido da direção do programa de atendimento, do defensor, do Ministério Público, do adolescente, de seus pais ou responsável.” (BRASIL, 2012, p. 10, grifos dos autores).

Estabelecemos, aqui, dois eixos de problematização a serem considerados para análise dos relatórios sociais requisitados no decurso dessas medidas socioeducativas de internação. Um deles refere-se ao caráter de discricionariedade da medida socioeducativa de internação e a contradição entre ambiente prisional e contexto avaliativo. $\mathrm{O}$ adolescente institucionalizado pela medida socioeducativa de internação precisa passar pelo ato de decisão política do juiz (o ECA não se pauta na diferença da infração e aplicação da medida socioeducativa) e depois de sentenciado, pela lógica institucional que executa a medida socioeducativa. Uma grande armadilha para o adolescente que se vê diante de uma linha tênue para uma dupla punição.

Para Silva (2011, p. 199) "há uma violência enorme do Estado e da sociedade contra esses sujeitos, que, já punidos pela ausência de acesso aos seus 'direitos’, acabam sendo novamente responsabilizados penalmente, aos moldes do paradigma da situação irregular.”

É dentro dos CENSEs, ou seja, num ambiente prisional, que se efetua a avaliação exigida pelo ECA e SINASE. Ela ocorre a partir de um relatório técnico multidisciplinar elaborado pela equipe técnica composta, principalmente, pelos profissionais de serviço social, psicologia e pedagogia. Os relatórios sociais são frutos de um contexto de avaliação da instituição em relação ao adolescente.

Essa contradição entre contexto prisional e avaliação social, há muito tempo, é discutida pelos profissionais do sistema penitenciário no momento de execução dos exames criminológicos, pois de acordo com Rauter (apud FÁVERO et al., 2004, p. 88-89): "toda a vida do condenado numa instituição prisional passa a subordinar-se a um exame e avaliação formulada por uma equipe integrada por cientistas humanos”.

Pretende-se, certamente, revestir esses procedimentos de certo grau de cientificidade, emanando daí sua confiabilidade. Para o autor, "[...] o sistema penitenciário pode, assim, travestir-se de uma roupagem científica, disfarçando até certo ponto, seu papel político-ideológico e modernizando seus métodos [...]” (RAUTER apud FÁVERO et al., 2004, p. 89).

Carvalho et al. (2004) ressaltam que as críticas mais comuns aos exames criminológicos, e que servem de reflexão para pensar a finalidade dos relatórios sociais avaliativos da medida socioeducativa de internação, são:

cientificidade questionável; risco de o instrumento ser fonte de arbitrariedades; instrumento de dominação escondida sob o manto da cientificidade; eticamente discutível, pois colhem-se informações particulares que passam a ser acessíveis a outras pessoas; [...] [utiliza-se de critérios como comportamento institucional e] a história de vida do sujeito como justificativa do ato criminoso [...] (CARVALHO et al., 2004, p. 16).

Por estes e outros aspectos, os profissionais do sistema penitenciário questionam "[...] a função do laudo, se não estaria sendo um instrumento simbólico para justificar o discurso falido de ressocialização que não vem se efetivando.” (GUINDANI, 2001, p. 42).

Todavia, essa discussão está muito longe de acontecer nos espaços de execução das medidas socioeducativas de privação de liberdade, tratando-se da realidade paranaense. É necessário superar o senso comum de que a prisão possibilita refazer valores de socialização, bem como, enfrentar os limites e fragilidades 
quando subalternizarmos a interpretação do direito penal juvenil em relação ao discurso da socioeducação, ou seja, é necessário constituir uma intervenção profissional para além dos objetivos institucionais.

O segundo eixo de problematização é o que se vincula às fragilidades do próprio ECA quando ele atribui ao juiz o livre arbítrio para a aplicação da medida socioeducativa, pois o Estatuto não fixou medidas específicas para cada tipo de infração e, também, não definiu prazo para cumprimento da medida socioeducativa, apenas, definiu que o prazo máximo para internação, de três anos, com reavaliações semestrais.

$\mathrm{O}$ adolescente fica à disposição do Estado sem saber por quanto tempo e dependerá de um relatório técnico multidisciplinar para decretar o encerramento de sua sanção social e penal. Esse movimento de progressão, regressão ou de acumulação de medidas socioeducativas, conforme Silva (2011) tende a ser arbitrário porque nele não existem critérios objetivos. Abre-se possibilidade para reprodução do poder discricionário do direito menorista pelos atores que compõem o sistema de responsabilidade penal juvenil, inclusive o assistente social.

Diante desta realidade, apoiados em Fávero et al. (2004), levantamos os seguintes questionamentos: O relatório social é uma extensão do poder de julgar do juiz? É o juiz que decide? E se assim o for, quem dá subsídios para ele decidir? Cabe ao assistente social assumir o papel do juiz na conclusão dos relatórios multidisciplinares ou propor alternativas para o atendimento do adolescente e sua família? Fávero et al. (2004) enfatizam que o saber de um profissional dentro de uma instituição o possibilita, inclusive, aplicar e direcionar a vida das pessoas. Uma realidade a ser "pensada, trabalhada, refletida e questionada” (FÁVERO et al., 2004, p. 91) pelos profissionais.

É inconteste que há uma ação interventiva mesmo após a conclusão do relatório social, pois, de acordo com Magalhães (2006, p. 34), “[...] essas relações continuam a ser processadas por meio dos autos, uma vez que estes são um meio de comunicação e é também por meio deles que o juiz pode julgar”. Este fato nos faz remontar ao nosso imprescindível compromisso ético-político para não cair nas teias das causalidades postas pelo trabalho alienado. A atuação profissional do assistente social não pode restringir-se a um mero preenchimento mecânico dos dados que, depois de escritos sob a forma de relatório, se tornam fatos inquestionáveis e interpretáveis a partir do que está registrado no documento.

O relatório social, na avaliação da medida socioeducativa de internação, tende a se constituir como uma forma silenciosa de poder. A não consciência profissional deste pressuposto, bem como o discurso socioeducativo utilizado para dar a face flexível e humanitária às medidas socioeducativas, reiteraram um modelo anacrônico de gestão institucional que materializa as ações do Estado punitivo e reproduz expressões do trabalho alienado e avesso à ética.

\section{Reflexões sobre a Dimensão Ética na Elaboração de Relatórios Sociais no CENSE: limites e possibilidades do exercício profissional do assistente social}

Se os relatórios sociais, por um lado, são orientados pela lógica e dinâmica institucional, podem ser também construídos a partir das perspectivas teórica, metodológica, ética e política que estão entre os eixos fundamentais do projeto profissional dos assistentes sociais. Essa orientação não pode ser obscurecida diante dos processos de universalização da alienação ocorridos no cotidiano e que, muitas vezes, são construídos em concomitância com o cumprimento de normas e políticas institucionais construídas sob a fusão eclética entre aspectos educativos e punitivos.

O trabalho do assistente social no momento de elaboração do relatório social revela limites à autonomia do profissional e desafios para a afirmação de um projeto profissional. É a partir desse binômio limites e possibilidades - que se configuram os dilemas éticos presentes nas escolhas e orientação das ações dos profissionais.

Identificar esses dilemas é fundamental para projetar respostas profissionais - e, entre elas, as construídas na elaboração de laudos, pareceres e relatórios sociais - em consonância com a dimensão ética e política que orienta o projeto profissional que se defende em reflexões teóricas sobre o Serviço Social na contemporaneidade.

Antes porém de identificá-los, cabe esclarecer o que consideramos como ética profissional. Não partilhamos do senso comum que tende a reproduzir uma análise fragmentada da ética, como se, no âmbito de uma profissão ela se caracterizasse como ética aplicada e, apenas em conformidade com as diferentes demandas postas às profissões pela natureza de sua inserção na divisão sócio técnica do trabalho. Por estes moldes, muitos dilemas éticos se dissolveriam, haja vista a tendência à orientação pragmática no cotidiano profissional.

Ao contrário dessa perspectiva, a dimensão ética possibilita o enfrentamento de aspectos axiológicos negativos que inviabilizam possibilidades de afirmação do gênero humano. Não nos referimos, aqui, à reflexão idealista sobre ética que se gesta no interior da sociabilidade burguesa e que tem como centralidade a responsabilização dos indivíduos sobre suas escolhas e comportamento, mas à ética na perspectiva da ontologia 
social para a qual os valores, escolhas e comportamentos nascem na relação dialética entre singularidade e universalidade que constituem a história.

As profissões, e entre elas o Serviço Social, nascem e consolidam-se a partir de necessidades históricas, tem particularidades e especificidades conforme as necessidades sociais a que respondem. Entretanto, no decorrer de diferentes contextos sócio históricos, o conjunto de respostas dadas pelos profissionais a estas necessidades conformam também a peculiaridade de cada profissão, ou seja, esse conjunto de respostas converge para a construção de projetos profissionais. Em consonância e no interior do projeto profissional do Serviço Social, situamos a dimensão ética do trabalho do assistente social na qual se materializa a complexa relação entre os objetivos profissionais e institucionais.

Nos relatórios sociais analisados em nossa pesquisa, a identificação dos objetivos da instituição aparece como determinante sobre os profissionais.

A alienação e a reprodução de valores do senso comum ou vinculados a um ideário conservador figuram dentre os limites concretos que se impõem frente à possibilidade de escolhas profissionais conscientes. A intervenção profissional não fica ilesa diante do processo de universalização da alienação e dos valores avessos ao humano genérico, como os reproduzidos por instituições sociais que, numa conjuntura conservadora, tendem a reproduzir valores cuja raiz está na defesa da sociabilidade burguesa e desigualdade de classes.

\section{O trabalho do assistente} social no momento de

\section{elaboração do relatório social} revela limites à autonomia do profissional e desafios para a afirmação de um projeto profissional. É a partir desse binômio - limites e possibilidades - que se configuram os dilemas éticos presentes nas escolhas $e$ orientação das ações dos profissionais.

É possível constatar, empiricamente ${ }^{6}$, que há uma linha tênue entre uma reflexão que de fato promova um processo de consciência profissional e aquela que se constrói a partir de processos alienantes. Uma constatação que não pode ser negligenciada na análise dos aspectos éticos constitutivos dos relatórios sociais, cuja elaboração, nos CENSEs, está essencialmente vinculada ao cotidiano profissional e tudo se resolve institucionalmente a partir deste documento ${ }^{7}$.

Não queremos refletir sobre as intervenções para as quais o assistente social é requisitado quando de sua inserção em instituições que atendem adolescentes em conflito com a lei, mas sinalizar aspectos desse processo interventivo, a partir de condições objetivas postas no cotidiano do trabalho na instituição para sinalizar formas de ultrapassar o campo pragmático de prescrições de ações e atitudes a serem cumpridas, pois são apresentadas como regras institucionais que convergem para a idealização das ações de reeducação social.

Interpreta-se aqui que as limitações do exercício profissional e, dentre estas, os dilemas éticos, não devem recair de forma exclusiva sob a subjetividade manifesta ou não do profissional. Isso, em nossa avaliação, é uma forma cruel de responsabilizar o indivíduo por contradições inerentes à dinâmica de uma instituição criada para amenizar aspectos da violência que derivam da própria sociabilidade burguesa.

Muitas são as contradições presentes no trabalho profissional na área sociojurídica e, dentre estas se destaca a dicotomia entre garantir acesso a direitos humanos e a necessidade de responsabilizar civil ou criminalmente aqueles que os violam; o que é explícito no cotidiano profissional do CENSE (BORGIANNI, 2014). Situar o trabalho dos assistentes sociais nesta perspectiva exige, a priori, uma análise crítica da necessidade desses direitos na sociabilidade burguesa e a suas garantias, ainda que nesta nessa sociabilidade, como emancipatórias.

Problematizar essa questão não é propor uma coleção de prescrições para o exercício profissional, haja vista que a dimensão técnico-operativa não pode ser analisada estanque ou hierarquizada em relação às dimensões ético-política e teórico-metodológica do exercício profissional.

A análise da dimensão ética na elaboração dos relatórios sociais não é a identificação de alternativas, ou um rol de sugestões para os efeitos desumanizadores do trabalho alienado por não convergir para a apresentação de uma proposta com viés moralizante e que sinalize saídas idealizadas como, por exemplo, a que vincula o exercício profissional crítico apenas à formação profissional.

No processo de construção de práticas profissionais conscientes dentro uma instituição que se apresenta vulnerável à incorporação ou atualização de práticas conservadoras ${ }^{8}$, faz-se necessário desnudar o imediatismo do cotidiano profissional. Ultrapassar a reprodução de ações rotineiras e que convergem para rotinas pré- 
estabelecidas é fundamental para suscitar reflexões e ações éticas emancipatórias. Caso contrário, afirma-se a tendência em diluir os objetivos profissionais nos objetivos institucionais e corre-se o risco de não apreender expressões da causalidade que movimentam a totalidade social e as ações dos profissionais tendem a figurar como mais uma expressão apenas causal tornando-se uma atividade alienada.

Segundo Meszáros (2006), a supressão da atividade alienada por intermédio da prática humana consciente não é uma relação estática de um meio com um fim, ou seja, não é uma cadeia causal mecanicista. Sua atividade não deixa de ser alienada em virtude do fato de ser consciente da alienação, pois se existe um objeto alienado estou necessariamente sujeito à alienação; todavia, mesmo que essa reflexão expresse uma forma alienada, isso não altera o fato de ser genuinamente humana, porque "[...] o único poder capaz de superar praticamente ('positivamente') a alienação da atividade humana é a própria atividade humana autoconsciente.” (MESZÁROS, 2006, p. 165). É na construção de atividades humanas conscientes, como uma forma de práxis, é que situamos a ética. Tal é a perspectiva analítica que nos move na identificação de alguns dos dilemas éticos dos assistentes sociais na elaboração de laudos e pareceres.

\section{Limites e possibilidades do exercício profissional no momento de elaboração dos relatórios sociais: dilemas éticos}

Foi possível identificar outros elementos a partir da leitura desses relatórios sociais. Dentre eles destacamos: apenas $17 \%$ dos assistentes sociais descrevem os dados coletados na realidade social num campo específico para Serviço Social dentro do relatório multidisciplinar e 83\% descrevem sua coleta de dados dissolvida no que eles denominam de aspectos psicossociais ou aspectos psicossociais e de permanência. É um fato que pode revelar dificuldades, e até limites, na compreensão da especificidade de trabalho profissional.

Na leitura de alguns relatórios sociais não foi possível identificar a peculiaridade da avaliação feita pelo assistente social ou a do psicólogo; ou se ambos escrevem juntos (aspectos psicossociais). Observamos a descrição de dados da realidade social concomitante com análises de cunho psicológico, num mesmo espaço, sem identificar a contribuição de cada área do saber, como podemos observar nas transcrições abaixo:

Em relação aos aspectos sociofamiliares, [adolescente A] reside com a genitora, Sra. [...] 51 anos, que exerce a função de diarista e com o pai, Sr. [...] 70 anos, que exerce a função de tapeceiro. Possui um irmão, por parte de mãe, que está em regime prisional, porém, também tem outros irmãos, por parte de pai que são adultos e casados, todos sem envolvimento com a criminalidade. O adolescente possui bom vínculo afetivo com os pais, visto que a mãe o visita com frequência na Unidade e o mesmo faz ligações frequentes para estes. [...] Quanto aos aspectos psicológicos, [adolescente A], se apresentou na internação um adolescente tranquilo, inteligente, franco e afetivo, apesar de demonstrar sofrer devido à privação de liberdade. Imaturo, até mesmo ingênuo, não apresentava de forma espontânea projetos ou planos concretos para seu futuro (RELATÓRIO SOCIAL $05^{9}$ ).

Não se questiona aqui a importância do trabalho interdisciplinar. Ao contrário, defende-se que ele é imprescindível no atendimento a adolescentes privados de liberdade, uma vez que, segundo Fávero et al. (2004), uma possibilidade concreta de intervenção profissional abalizada por orientações ético-políticas supõe o trabalho interdisciplinar numa dimensão de trabalho coletivo. No entanto, apresentamos um primeiro dilema ético: É possível que haja essa atuação sem dissolver as especificidades profissionais no denominador técnico do CENSE, em questões que envolvam, por exemplo, situações de sigilo profissional?

Para Magalhães (2006), embora os profissionais de diversas áreas de saber (assistentes sociais, psicólogos, pedagogos e outros) observem o mesmo fato, devem encaminhar suas análises pontuando mais expressivamente a ótica de suas respectivas áreas de competência; no caso, o relatório social precisa apontar a matéria do Serviço Social, ou seja, o assistente social tem sua natureza reconhecida e sancionada na divisão social do trabalho como uma profissão interventiva e institucionalizada para responder às diversas expressões da questão social pela via das políticas sociais do Estado burguês.

Sendo a violência uma expressão das refrações da questão social evidenciada no cotidiano do CENSE, ela é enfrentada de forma parcializada e fragmentada, constituindo, assim, como uns dos aspectos da realidade objetiva do exercício profissional na sua intervenção direta com os indivíduos sociais que sofrem os efeitos desta contradição entre capital/trabalho.

No que tange à especificidade da atuação profissional do assistente social, procurou-se identificar quais os critérios que subsidiam sua avaliação. Identificamos que os principais argumentos utilizados no relatório social estão vinculados, principalmente, às fragilidades familiares (em 80\% é mencionado); a adaptação dos 
adolescentes às normas institucionais/sociais (65\%); e ao uso de drogas (50\%). Em apenas 15\% dos relatórios sociais, o acesso precário as políticas sociais é apontado como uma variável de análise.

Diante desta exposição, analisamos que a centralidade da realidade social do adolescente aparece restrita ao universo familiar e ao peso que a conduta disciplinar na instituição assume na elaboração dos relatórios sociais por serem aspectos que merecem reflexão, no campo da ética profissional. Destacamos, portanto, um segundo dilema ético: Qual a maneira de ultrapassar o conservadorismo ético que imputa à família a única responsabilidade pela situação do adolescente?

Quanto à centralidade na responsabilidade da família, segundo Pereira (2013) é preciso desconstruir no nosso cotidiano profissional a reprodução do senso comum que imputa à família todos os tributos de suas dificuldades materiais e afetivas. Essa interpretação reitera uma leitura que são apenas as famílias os responsáveis por problemas emocionais, desvios de comportamento (infracional) ou fracasso escolar do adolescente; sem situar esses problemas como parte de uma totalidade concreta e, consequentemente, como mediações de um movimento do real que aparecem na falsa forma de problemas individuais ou casos.

A dimensão ético-política tende a ser obscurecida no cotidiano profissional e retomam-se julgamentos morais idealizados sob os que estão no caminho do bem, muitas vezes identificados como os veiculados por essa sociabilidade e, os do caminho do mal, identificado como transgressões à moral dominante.

Uma possibilidade concreta dessa desconstrução pode se materializar por intermédio dos relatórios sociais, os quais, embora não expressem a amplitude do trabalho realizado pelo profissional, cristalizam-se como verdades que podem ser utilizadas para reproduzir práticas investigatórias e policialescas por outros profissionais que compõem o sistema de responsabilização penal juvenil e contrárias aos princípios fundamentais, direitos e deveres postos no atual código de ética profissional dos assistentes sociais.

O peso da conduta institucional do adolescente na avaliação da medida socioeducativa de internação nos coloca diante de um terceiro dilema. Trata-se de uma questão complexa que não se esgota, com as reflexões que ora apresentamos. Há, durante a inserção do adolescente na instituição, uma série de comportamentos prescritos por esta instituição e que orientam a execução da medida socioeducativa. $\mathrm{O}$ assistente social, como um técnico neste espaço sócio ocupacional, analisa a adesão dos adolescentes a comportamentos considerados positivos, do ponto de vista do que se chama ressocialização.

Há, aqui, uma série de dilemas e aspectos éticos, dentre os quais destacamos o fato do profissional se isentar que também participa do disciplinamento do adolescente na instituição sendo a disciplina o único critério para a avaliação da medida socioeducativa; a reiteração, no exercício profissional, de ações policialescas e atitudes de caráter investigatório que não estão entre suas atribuições privativas e que são contrárias a deveres fundamentais postos no código de ética profissional dos assistentes sociais.

Quanto ao primeiro aspecto, o problema não é, de acordo com Fávero et al. (2004), colocar o preso dentro da ordem disciplinar da instituição, mas sim o assistente social se isentar da responsabilidade de que ele também institui a ordem da mesma, ou seja, "não podemos nos esquecer, não podemos lavar as mãos. Somos custodiadores também” (FÁVERO et al., 2004, p. 130). Ainda de acordo com as autoras, “[...] a disciplina é, basicamente, um instrumento da moral.” (FÁVERO et al., 2004, p. 130).

Neste sentido,

nosso trabalho também é de disciplinamento. Entretanto, existem disciplinas e disciplinas. Nos deparamos em várias situações da vida com a disciplina, como por exemplo, num jogo, numa partida de futebol. Porém, qual a concepção de disciplina que deve pautar nossas ações? Essa é a questão! Será a mesma moral de disciplina que a instituição possui? (FÁVERO et al., 2004, p. 130).

Essa reflexão é necessária para o cotidiano institucional do CENSE, uma vez que a partir do nosso exercício profissional, foi possível observar uma tendência institucional em consolidar uma pretensa oposição de interesses profissionais entre os que compõem a equipe técnica (assistente social, pedagogos, psicólogos) e os profissionais que executam a função de educador social.

Os técnicos são identificados como os defensores, apenas, dos direitos humanos dos adolescentes privados de liberdade e os educadores sociais como os que executam as ações policialescas. Nossa interpretação questiona esta polaridade. Abalizar o exercício profissional na dimensão ética é compreender que todos executam a função coercitiva, sancionatória e punitiva, e que por isso, todos, independentemente de qual grupo profissional, também apresentam condições na execução coletiva de uma medida socioeducativa de internação humanizada e orientada por princípios éticos.

Reafirmar essa cisão entre técnico e educador social é cimentar processos de alienação no cotidiano do exercício profissional. Iasi (2011) aponta que a superação inicial da alienação se dá no grupo, isto é, na identidade com o outro que surge possibilidade para introjeção de novos valores, ainda que o grupo partilhe da 
consciência alienada. A objetividade deste momento histórico exige reflexão teórica e prática com vistas a constituir um exercício profissional capaz de resistir em assumir a forma acabada, como por exemplo, o cotidiano institucional do CENSE.

Outro dilema está na probabilidade de reiteração do exercício profissional a ações policialescas. Para Goffman (1961, p. 22), exercício profissional, ações policialescas, instituições com características de fechamento, na tentativa de se consolidar como "estufas para mudar pessoas" provocam insatisfação nos especialistas que participam desta intervenção, hipoteticamente humanitária, pois não exercem sua profissão como idealizam, mas sim, são usados para dar a chancela de especialistas ao sistema de privilégios. Nesse contexto contraditório e complexo que amarram outras teias de causalidades, esse profissional geralmente é chamado pela instituição para "[...] impor a obediência aos internados e, ao mesmo tempo, dar a impressão de que os padrões humanitários estão sendo mantidos e os objetivos racionais da instituição estão sendo realizados.” (GOFFMAN, 1961, p. 84).

Esse dilema provoca sofrimento ético nos profissionais inseridos em instituições como o CENSE. A disciplina institucional, sobre premissas ético-políticas, não deve ser o único aspecto que orienta a elaboração do relatório social dentro do CENSE. Fundamentados pelos valores do projeto profissional nossa luta é por outro tipo de controle social. Nas palavras de Silva (2011, p. 233), "será um tipo histórico de controle social baseado na lógica da sociabilidade do trabalho concreto, da emancipação humana e não da sociabilidade autoritária.”

Com base em Carvalho et al. (2004), afirmamos que, o relatório social avaliativo é, sobretudo, um desafio ético. Sua construção apresenta-se como um impasse tanto para os adolescentes como para os profissionais. O adolescente identifica dentro da esfera institucional que o relatório é sua possibilidade concreta de liberdade, e diante disso, se atém às questões de ordem prática e imediata, como por exemplo, bom comportamento institucional. Quanto aos profissionais, é imprescindível a constante preocupação sobre a forma de interpretar os dados empíricos e sua necessária conexão com nexos estruturais e conjunturais da totalidade social.

Neste contexto, é possível atuar além do controle sociopenal na execução das medidas socioeducativas? O disciplinamento é inerente à instituição que executa medida socioeducativa de internação cuja natureza é de conteúdo coercitivo, sancionatório e punitivo, para restabelecer a coesão social. Todavia, o exercício profissional não se limita a essas ações, é preciso uma decisão ética sobre o que vai ser escrito ou não no relatório social.

O grande desafio ético do assistente social, inserido na área sociojurídica, está em interpretar que suas atribuições não se resumem em práticas policiais, de fiscalização de comportamentos e de extração de verdades jurídicas. O primeiro passo, para enfrentar o crescente investimento na penalização e judicialização das expressões da questão social, de acordo com Fávero (2013), é desfazer receitas institucionais.

Se por um lado, neste cotidiano profissional se assiste ao um aumento das responsabilidades profissionais, decorrente de novos marcos regulatórios e da crescente atuação do Estado punitivo na esfera de criminalização da pobreza, provocando sofrimento ético-político nos profissionais inseridos nestas instituições; por outro lado, esse mesmo cotidiano abre possibilidade para exercício profissional cuja sustentação ética é a luta pela garantia de direitos sociais positivados, reiterando uma relação de contínuo e descontínuo sobre os limites e possibilidades da ação, em uma perspectiva interdisciplinar, sustentada por uma visão crítica da realidade.

Conclui-se, portanto, de acordo com Silva (2011), não é o trabalho que está em crise, mas sim, uma forma histórica - trabalho assalariado. Nossa "[...] recusa é pelo trabalho alienado (abstrato) e não pelo trabalho emancipado (concreto).” (SILVA, 2011, p. 65). E para a conquista deste trabalho, elucidado por Meszáros (2006), o trabalho criativo deve estar para além do capital.

Neste sentido, o trabalho dentro do CENSE, para seja capaz de objetivar por si, mesmo em uma forma alienada, deve ser realizado não, apenas, na defesa dos direitos humanos dos adolescentes, mas também, em um processo de construções coletivas que envolvem os socioeducadores (educadores sociais, professores, direção), na tentativa de instituir uma nova prática capaz de provocar rupturas com a moralidade hegemônica. Enfim, são questões que nos movem para reflexões futuras sobre o exercício profissional na perspectiva de “[...] ações abalizadas, intelectualmente responsáveis e fecundas [...]” (FORTI; GUERRA, 2013, p. 3).

\section{Considerações Finais}

As decisões profissionais, para as quais somos convocados a nos manifestar, cotidianamente, num CENSE, exigem uma reflexão crítica sobre ética profissional. A partir dela, torna-se possível adotar uma atitude crítica frente aos esquemas recebidos ou nem os perceber como esquemas no cotidiano profissional. Não há como pensar em um exercício profissional, neste espaço sócio ocupacional, que não seja precedido de um diálogo sistemático entre ética, cotidiano e exercício profissional competente e qualificado.

Acredita-se que, estabelecer uma discussão ética, dentro deste espaço sócio-ocupacional pode contribuir para motivar o processo de consciência dos profissionais. Nesse sentido, entender os fundamentos teóri- 
co-metodológicos que subsidiam o delineamento das atribuições profissionais nos espaços socioeducativos, bem como dos instrumentos utilizados para cumpri-las, é fundamental para construção cotidiana de uma perspectiva ética e política crítica à sociabilidade burguesa. Por intermédio desta dimensão teórico-metodológica e ético-política que o profissional pode ter consciência dos alicerces que fundamentam o discurso falacioso da socioeducação e a ressocialização como possibilidades de intervenção profissional.

Enfrentar essa objetividade não é descartar o discurso institucional do cotidiano profissional. Ao contrário, ele será na sua grande parte, uma possibilidade de enfrentamento das violações dos direitos humanos sofridos pelos adolescentes infratores; no entanto, não deve ser compreendido como única possibilidade de interpretação da realidade social.

A interpretação crítica do exercício profissional pode abrir possibilidades de ações profissionais que no cotidiano venham a fortalecer o polo de defesa dos direitos humanos (entendido, aqui, como a defesa dos direitos de um adolescente de não ficar preso pela perversidade de dinâmica societária) e, em contrapartida, enfrentar tendências que reafirmam o ciclo perverso das instituições punitivas do Estado capitalista burguês. A ética pode ser um instrumento teórico-prático para enfrentamento deste ciclo, dentre outros aspectos, porque eleva o indivíduo social de forma a entender que sua particularidade se inscreve na universalidade do gênero humano.

\section{Referências}

BORGIANNI, E. Prefácio. In: FÁVERO, E.; GOIS, D. A. (Org.). Serviço Social e temas sociojurídicos: debates e experiências. Rio de Janeiro: Lumen Juris, 2014. p. XV-XVII.

BRASIL. Lei n. 8.069, de 13 de julho de 1990. Dispõe sobre o Estatuto da Criança e do Adolescente e dá outras providências. Diário Oficial [da] República Federativa do Brasil. Brasília, DF, 16 jul. 1990. Disponível em: <http://www.planalto.gov.br/ccivil_03/leis/ L8069.htm>. Acesso em: 24 out. 2016.

. Lei n. 12.594, de 18 de janeiro de 2012. Institui o Sistema Nacional de Atendimento Socioeducativo (SINASE), regulamenta a execução das medidas socioeducativas destinadas a adolescente que pratique ato infracional. Diário Oficial [da] República Federativa do Brasil. Brasília, DF, 19 jan. 2012. Disponível em: <http://www.planalto.gov.br/ccivil_03/_ato2011-2014/2012/lei/l12594.htm>. Acesso em: 24 out. 2016.

CARVALHO, J. L. et al. O Exame criminológico: notas para sua construção. In: CONSELHO FEDERAL DE SERVIÇO SOCIAL (Org.). O estudo social em perícias, laudos e pareceres técnicos: contribuição ao debate no Judiciário, Penitenciário e na Previdência Social. 2. ed. São Paulo: Cortez, 2004. p. 12-17.

FÁVERO, E. T. Serviço Social e o campo sociojurídico: reflexões sobre o rebatimento da questão social no trabalho cotidiano. In: FORTI, V.; GUERRA, Y. (Org.). Serviço Social: temas, textos e contextos. 4. ed. Rio de Janeiro: Lumens Juris, 2013. p. 135-146.

. et al. As implicações ético-políticas do processo de construção do estudo social. Em foco: o Serviço Social e o Sistema Sociojurídico, Rio de Janeiro, CRESS/RJ, n. 2, p. 73-133, dez. 2004.

FORTI, V.; GUERRA, Y. “Na prática a teoria é outra?” In: (Org.). Serviço Social: temas, textos e contextos. 4. ed. Rio de Janeiro: Lumens Juris, 2013. p. 3-22.

GOFFMAN, E. Manicômios, prisões e conventos. São Paulo: Perspectiva, 1961.

GUINDANI, M. K. A. Tratamento Penal: a dialética do instituído e do instituinte. Serviço Social e Sociedade, São Paulo, n. 67, p. 3852, set. 2001.

IASI, M. L. Reflexão sobre o processo de consciência. In: Ensaios sobre consciência e emancipação. 2 ed. São Paulo: Expressão Popular, 2011. p. 7-45.

INSTITUTO DE AÇÃO SOCIAL DO PARANÁ. Gestão de Centro de Socioeducação. Curitiba: IASP, 2006. (Cadernos do IASP). Disponível em: <http://www.dease.pr.gov.br/arquivos/File/GestCense.pdf> . Acesso em: 24 out. 2016.

MAGALHÃES, S. M. Avaliação e linguagem: relatórios, laudos e pareceres. 2. ed. São Paulo: Veras, 2006.

MESZÁROS, I. A teoria da alienação em Marx. São Paulo: Boitempo, 2006.

PARANÁ. Decreto n. 7.663, de 15 de dezembro de 2006. Curitiba, PR, 15 dez. 2006. Disponível em: <http://www.leisestaduais.com.br/ pr/decreto-n-7663-2006-parana-dando-nova-redacao-ao-artigo-32-do-decreto-959-de-28-de-junho-de-1995-que-trato-do-regulamentodo-iasp>. Acesso em: 24 out. 2016.

Portaria n. 027, de 13 de fevereiro de 2007. Curitiba, PR, 13 fev. 2007. Disponível em: <http://socioeducadores-pr.blogspot.com.br/ 2012/08/portaria-n-02707.html>. Acesso em: 24 out. 2016.

PEREIRA, T. M. D. Quando o camburão chega antes do SAMU: notas sobre os procedimentos técnico-operativos do Serviço Social. In: FORTI, V; GUERRA, Y. (Org.). Serviço Social: temas, textos e contextos. 4. ed. Rio de Janeiro: Lumens Juris, 2013. p. $163-182$.

SILVA, M. L. O. Entre proteção e punição: o controle sociopenal dos adolescentes. São Paulo: UNIFESP, 2011. 


\section{Notas}

1 Optamos por deixar no anonimato o fórum que autorizou o acesso aos relatórios sociais.

2 Uma constatação empírica possível com a inserção de uma das autoras que, quando da construção da pesquisa, trabalhava como assistente social no CENSE e tinha como uma de suas atribuições profissionais a emissão de relatórios sociais.

3 Atualmente, o Estado do Paraná conta com 19 (dezenove) unidades que executam internação e internação provisória e 8 (oito) casas de Semiliberdade.

4 Conforme Portaria 027, de 13 de fevereiro de 2007 (PARANÁ, 2007).

5 Tal afirmação é fruto de uma reflexão contínua sobre exercício profissional de uma das autoras deste artigo, nesta instituição há, aproximadamente, dez anos.

6 Uma constatação que se dá a partir da vivência das pesquisadoras no cotidiano institucional das instituições em que trabalham como assistentes sociais em diferentes atribuições privativas: no interior de uma instituição que executa media socioeducativa em regime fechado e outra em uma instituição de ensino público.

7 Esta afirmação é fruto de uma reflexão contínua sobre nosso exercício profissional desenvolvido nesta instituição há aproximadamente dez anos.

8 Referimo-nos aqui a um contexto institucional em que aspectos que se punham como pilares do Serviço Social, no seu período de adesão aos ideais metafísicos e funcionais da ordem burguesa, aparecem cotidianamente. Dentre esses, a tendência em reatualizar o mapeamento (diagnóstico) do que denominava de situação social problema para a qual se requisitava, entre outros aspectos, o ajustamento de personalidade ou a ajuda psicossocial.

9 Trata-se de um dos 18 relatórios sociais de acesso restrito analisados neste artigo, conforme mencionado anteriormente.

\section{Gabriella Mariano Munhoz Zeneratti}

gmmzeneratti@mppr.mp.br

Mestrado em Serviço Social pela Universidade Estadual de Londrina (UEL)

Assistente social do Ministério Público do Estado do Paraná (MPPR)

\section{MPPR}

$9^{a}$ Unidade Regional de Apoio Técnico Especializado - URATE/PV

Rua Antônio Vendramin, 1770, Jardim Aeroporto

Paranavaí - Paraná - Brasil

CEP: 87.704-160

\section{Olegna de Souza Guedes}

olegnasg@gmail.com

Doutorado em Serviço Social pela Pontifícia Universidade Católica de São Paulo (PUC-SP)

Docente do Programa de Pós-Graduação em Serviço Social e Política Social da Universidade Estadual de Londrina (UEL)

\section{UEL}

Rodovia Celso Garcia Cid, PR 445, Km 380 - Campus Universitário

Cx. Postal 10.011

Londrina - Paraná - Brasil

CEP 86.057-970 